\title{
PRELIMINARY CONSTRUCTION COST ESTIMATE IN YEMEN BY ARTIFICIAL NEURAL NETWORK
}

\author{
Waled HAKAMI ${ }^{1}$, Awad HASSAN ${ }^{2}$ \\ ${ }^{1}$ University of Science and Technology, Sana'a, Yemen \\ ${ }^{2}$ Sudan University of Science and Technology, Khartoum, Sudan \\ Corresponding author's e-mail: w_g2006@yahoo.com
}

\begin{abstract}
The construction industry in Yemen is currently facing challenges associated with rapid development of technology; thus, cost estimation is considered a key factor that should align with this technological advancement. The main problem in the area of preliminary estimate in Yemen is how to make estimate accurately. The aim of this study is to analyse a modern method of preliminary cost estimation in Yemen to prove its efficiency over the traditional method. Therefore, a wide range of literature sources regarding the preliminary estimates using Artificial Neural Network (ANN) as a modern technique is considered. Both qualitative and quantitative approaches were adopted in this study depending on the theoretical premises discussed in literature and the ANN technique, respectively. The independent variables were chosen in the course of literature review. The collected data were classified and processed regarding the ANN constraints and encoded for building and analysis of the ANN model. NeuroSolution 6 software was used to build, train, and test the network as well as to perform sensitivity analysis. In addition, the results of training, testing, and sensitivity analysis were obtained and discussed showing high effectiveness of accurate estimates with less than $1 \%$ error. The ANN model is a more powerful technique for estimating costs in the preliminary stage that should be used in the developing countries instead of the traditional methods.
\end{abstract}

Keywords: Accurately, Performance, Sensitivity analysis, Training, Testing.

\section{INTRODUCTION}

Many factors affect the success of a construction project, such as time, quality and cost (Finch, Yu, Shen, Kelly, \& Hunter, 2005); thus, cost estimation is the most important activity during various project stages. Cost estimation may be a challenging task in conditions of limited availability of information. Lack of time and information, as well as the complexity of the building project considered for cost estimation often lead to poor performance in estimates (Brook, 2011). Samphaongoen (2010) states that the accuracy of the preliminary estimate is often \pm 10 to $20 \%$. In Yemen, engineers estimate their projects in the preliminary stage using traditional methods, i.e. unit price of square meter and analogous methods, which often leads to inaccurate estimates. In order to overcome this problem, a modern preliminary estimate (modern technique) to be adopted in Yemen is investigated to prove its efficiency over the traditional methods. This study investigates the preliminary estimate made using Artificial Neural Network (ANN). 
According to Pawar (2007), cost estimates can be classified according to the function of the estimate at various stages of the project. The preliminary estimate helps the estimators to satisfy client requirements to determine the budget of their project. Early cost advice is also valuable in drawing up the project information. It will affect cost implications of design decisions and answer the first question that is asked by client, namely, "How much will the project cost me", which in its turn helps in decision-making. Then, the client can decide whether to proceed with the project or not. Consequently, the cost estimation mission becomes desirable and crucial, especially during the preliminary (conceptual) stage, in which the project scope is not finalized and there is very limited information (Kirkham, Brandon, \& Ferry, 2015; Sonmez, 2004).

Hunter (2014) examined cost estimation variables in the preliminary project stage and considered those variables for road projects. Because the projects were related to construction and maintenance of roads, many variables are not relevant for this study. However, three out of 12 variables he examined were adopted as most important, including complexity, project type, and construction cost.

In addition, Shehatto (2013) discussed the need of estimation to ensure high degree of accuracy without detailed information or drawings to satisfy the parties of the project (Clients, Donors, Consultant and Contractors). The ANN model, which was used as a new approach in cost estimation, was utilised to identify significant parameters for building project costs. The ANN model considers eleven significant parameters as independent input variables that affect one dependent output variable - "project cost". These variables ranged according to the degree of their significance are as follows: area of a typical floor, number of storeys, building use, type of foundation, number of elevators, slab type (solid, ribbed, etc.), type of external finishing, presence of HVAC and false ceiling, type of tiles, type of electricity works, and type of mechanical works.

Furthermore, Kim, Shin, Kim, and Shin (2013) stated that cost estimation in the preliminary stage is not accurate due to incomplete drawings. Consequently, ten variables were adopted to be examined for school projects in the UK in order to estimate the costs in the preliminary stage. Those variables are year, budget, school levels, land acquisition, class number, building area, gross floor area, storey, basement floor, and floor height. Three different techniques have been applied and compared in terms of the accuracy of three estimating techniques (regression analysis (RA), neural network (NN), and support vector machine techniques (SVM)) by performing estimations of construction costs. Using historical data, the NN model shows more accurate estimation results than the RA and SVM models.

At the same time, Cheng, Tsai, and Hsieh (2009) used the neural network model to estimate the house projects relying on ten quantitative and qualitative variables for their model, which are floors underground, total floor area, floors aboveground, site area, number of households, households in adjacent buildings (quantitative factors), soil condition, seismic zone, interior decoration, and electromechanical infrastructure (qualitative factors).

The function of ANN is to simulate the biological human brains (Kriesel, 2005). Qualitative and quantitative methods were used to substantiate the outcome of this study. The results of this study will provide interesting insights about the 
effectiveness and efficiency of the ANN model to make preliminary construction cost estimates in Yemen.

\section{METHODOLOGY}

The qualitative and quantitative approaches were adopted. The research methods used in this study include literature review (qualitative) and ANN technique (quantitative). Three factors were adopted to construct the model of this study:

1. The variables must be at the preliminary stage and fit the context of this study (Arab, 2011);

2. The independent variables must reflect the client requirements (the voice of the client rather than the voice of design) (Emsley, Lowe, Duff, Harding, \& Hickson, 2002);

3. Independent variables that reflect both the voice of the client and design can be adopted.

Based on the above-mentioned three factors, this study adopted seventeen independent variables elicited in the course of the literature review of the recent studies. The variables are listed in Table 1.

Table 1. The selected dependent and independent variables (developed by the author)

\begin{tabular}{|c|c|}
\hline Dependent variable & Independent variables \\
\hline \multirow{17}{*}{ Preliminary cost estimate } & Complexity \\
\hline & Project type \\
\hline & Area of floors \\
\hline & Number of storeys \\
\hline & Type of foundation \\
\hline & Number of elevators \\
\hline & Slab type \\
\hline & Type of external finishing \\
\hline & Interior decoration \\
\hline & Type of HVAC system \\
\hline & Type of tiles \\
\hline & Type of electricity works \\
\hline & Type of mechanical works \\
\hline & Basement floor \\
\hline & Floor height \\
\hline & Site area \\
\hline & Project location \\
\hline
\end{tabular}

Consequently, these seventeen independent variables were chosen as variables of the preliminary estimate model (ANN model) of construction projects in Yemen. The authors designed the cost form sheet to collect the data on the implemented projects with regard to the variables listed in Table 1. 


\subsection{Data Collection}

The cost form sheets collected from 136 implemented projects (historical data) would be used in the ANN model. Four conditions were observed controlling the process of data collection:

1. The projects were implemented from 2011 to 2015;

2. The projects should be finished and in use (Arafa \& Alqedra, 2011);

3. The prices of project currency should be unified (Shehatto, 2013);

4. The maximum number of projects in one category does not exceed $95 \%$ (Islam, Zhou, \& Li, 2009).

SPSS IBM 19 was used to analyse and classify the collected data for independent variables from the survey, see Table 1 of Appendix 1 for results.

\subsection{Constraints of the ANN Model}

There were some constraints in using the historical data in the ANN (Shehatto, 2013), which were:

- The inputs of variables were limited to the collected data;

- Sufficient number of projects should be available for each variable;

- Any new variable that does not belong to the adopted model would not be handled.

Therefore, the limitations of the ANN model could be summarized according to the inputs of variables; when the input was registered in only one case (136 projects), the variable should have been excluded from the analysis, but it was still present in the ANN model implicitly. On the other hand, any inputs that did not appear in the collected data were excluded from the range of variable inputs and the variable still was present in the ANN analysis, which will be clearly shown in Table 2.

Table 2. Constraints of the variables (developed by the author)

\begin{tabular}{|l|l|l|l|l|}
\hline Variable & $\begin{array}{l}\text { Excluded } \\
\text { input }\end{array}$ & Included input & $\begin{array}{l}\text { Implicitly } \\
\text { present in the } \\
\text { ANN model } \\
\text { and excluded } \\
\text { from analysis* }\end{array}$ & Remarks \\
\hline Project type & Mosque & $\begin{array}{l}\text { Administration, } \\
\text { commercial, } \\
\text { educational, } \\
\text { residential, and } \\
\text { health centre. }\end{array}$ & No & $\begin{array}{l}\text { Only one input } \\
\text { excluded }\end{array}$ \\
\hline Project position & Desert & Mountain, coastal & No & $\begin{array}{l}\text { Only one input } \\
\text { excluded }\end{array}$ \\
\hline $\begin{array}{l}\text { Type of } \\
\text { foundation }\end{array}$ & $\begin{array}{l}\text { Strip, raft, } \\
\text { and pile }\end{array}$ & Pad & Yes & $\begin{array}{l}\text { Only one } \\
\text { recognized input for } \\
\text { all projects }\end{array}$ \\
\hline $\begin{array}{l}\text { Interior } \\
\text { decoration }\end{array}$ & Luxury & Basic & Yes & $\begin{array}{l}\text { Only one } \\
\text { recognized input for } \\
\text { all projects }\end{array}$ \\
\hline
\end{tabular}




\begin{tabular}{|l|l|l|l|l|}
\hline $\begin{array}{l}\text { Type of } \\
\text { external } \\
\text { finishing }\end{array}$ & $\begin{array}{l}\text { None, } \\
\text { aluminium, } \\
\text { and } \\
\text { cladding. }\end{array}$ & $\begin{array}{l}\text { Normal plaster, } \\
\text { stones }\end{array}$ & No & $\begin{array}{l}\text { Only two inputs } \\
\text { excluded }\end{array}$ \\
\hline Type of HVAC & Central & $\begin{array}{l}\text { None, window, } \\
\text { split }\end{array}$ & No & $\begin{array}{l}\text { Only one input } \\
\text { excluded }\end{array}$ \\
\hline Type of tiles & $\begin{array}{l}\text { Terrazzo, } \\
\text { porcelain }\end{array}$ & Ceramic, granite & No & $\begin{array}{l}\text { Only two inputs } \\
\text { excluded }\end{array}$ \\
\hline $\begin{array}{l}\text { Type of } \\
\text { electricity } \\
\text { works }\end{array}$ & Luxury & Basic & Yes & $\begin{array}{l}\text { Only one } \\
\text { recognized input for } \\
\text { all projects }\end{array}$ \\
\hline $\begin{array}{l}\text { Type of } \\
\text { mechanical } \\
\text { works }\end{array}$ & Luxury & Basic & Yes & $\begin{array}{l}\text { Only one } \\
\text { recognized input for } \\
\text { all projects }\end{array}$ \\
\hline No of elevators & 0 & 0 & No & $\begin{array}{l}\text { No recognized } \\
\text { inputs for all } \\
\text { projects }\end{array}$ \\
\hline Basement & Exists & Does not exist & Yes & $\begin{array}{l}\text { Only one } \\
\text { recognized input for } \\
\text { all projects }\end{array}$ \\
\hline *This variable was not analysed but belonged to the ANN model implicitly; it does not affect the results of the model. \\
\hline
\end{tabular}

So, the data became constrained and ready for encoding.

\subsection{Data Encoding}

The ANN model deals only with numerical inputs, therefore, the inputs were transformed into numeric format (Kshirsagar and Rathod, 2012; Principe, Lefebvre, Lynn, Fancourt, \& Wooten, 2010); thus, the data had to be encoded to increase the effectiveness of the ANN model performance, as shown in Table 3.

Table 3. Data encoding (developed by the author)

\begin{tabular}{|c|c|c|c|}
\hline No. & Variable & Variable's inputs (encoding) & Code \\
\hline \multirow{5}{*}{1} & \multirow{5}{*}{ Project type } & Administration & 1 \\
\hline & & Commercial & 2 \\
\hline & & Educational & 3 \\
\hline & & Residential & 4 \\
\hline & & Health centre & 5 \\
\hline \multirow{2}{*}{2} & \multirow{2}{*}{ Degree of complexity } & Complex & 1 \\
\hline & & Normal & 0 \\
\hline \multirow{10}{*}{3} & \multirow{10}{*}{ Site area, $\mathrm{m}^{2}$} & $200-300$ & 1 \\
\hline & & $301-400$ & 2 \\
\hline & & $401-850$ & 3 \\
\hline & & $851-1200$ & 4 \\
\hline & & $1201-1350$ & 5 \\
\hline & & $1351-1600$ & 6 \\
\hline & & $1601-2050$ & 7 \\
\hline & & $2051-2300$ & 8 \\
\hline & & $2301-2750$ & 9 \\
\hline & & $2751-11700$ & 10 \\
\hline 4 & Project position & Mountain & 1 \\
\hline
\end{tabular}




\begin{tabular}{|c|c|c|c|}
\hline No. & Variable & Variable's inputs (encoding) & Code \\
\hline & & Costal & 2 \\
\hline \multirow{7}{*}{5} & \multirow{7}{*}{ Floor area, $\mathrm{m}^{2}$} & $100-200$ & 1 \\
\hline & & $201-250$ & 2 \\
\hline & & $251-300$ & 3 \\
\hline & & $301-350-400$ & 4 \\
\hline & & $401-500$ & 5 \\
\hline & & $501-550$ & 6 \\
\hline & & $>550$ & 7 \\
\hline 6 & Number of storeys & From 1-4 & $1,2,3,4$ \\
\hline \multirow{5}{*}{7} & \multirow{5}{*}{ Floor height, m } & 3.0 & 1 \\
\hline & & 3.2 & 2 \\
\hline & & 3.3 & 3 \\
\hline & & 3.4 & 4 \\
\hline & & 3.5 & 5 \\
\hline \multirow{3}{*}{8} & \multirow{3}{*}{ Slab type } & Drop beams & 1 \\
\hline & & hollow block & 2 \\
\hline & & Flat & 3 \\
\hline \multirow{2}{*}{9} & \multirow{2}{*}{ Type of external finishing } & Normal plaster & 1 \\
\hline & & Stones & 2 \\
\hline \multirow{3}{*}{10} & \multirow{3}{*}{ Type of HVAC } & None & 1 \\
\hline & & Window & 2 \\
\hline & & Split & 3 \\
\hline \multirow{2}{*}{11} & \multirow{2}{*}{ Type of tiles } & Ceramic & 1 \\
\hline & & Granite & 2 \\
\hline
\end{tabular}

It is important to note that encoding the data made it suitable for analysis by the ANN.

\subsection{Building the Artificial Neural Network (ANN)}

In this study, the NeuroSolution 6 was used to build and analyse the ANN model, which demonstrated a good performance and output. Specifically, NeuroSolution 6 for Excel was used to build the ANN model; it was easier and more flexible in use for both training and testing. After the data were prepared, the sequential steps were to create the initial network by choosing the multilayer perceptron (MLP), which consisted of inputs (independent variables), one hidden layer, and output (dependent variable), it is the most common type used in cost estimate. To perform the analysis, the data should be set into three sets, namely, training set $-70 \%$; cross-validation set $-15 \%$, and test set $-15 \%$ (Dowler, 2008). Generally speaking, the training set and cross-validation set were used to train the model through learning to modify the network weights in order to minimize the network error through monitoring with cross validation dataset. The "Back Propagation" algorithm, which was used to train the network, belongs to the realm of supervised learning. Consequently, it was adopted in this study to train the multilayer network, which is concerned with feed forward the network structure (Ashwood, 2013). The error of training can be expressed by the mean squared error (Willumsen, Oehmen, Stingl, \& Geraldi). To conduct the training phase, the normalization of the training data was recognized to improve the training performance of the network by NeuroSolution software. Moreover, separately, the 
test dataset was used to measure the generalization of the network as well as the network's performance.

Furthermore, the testing set was used to confirm that the network had learned (Shehatto, 2013).

To determine the accuracy of the estimate in the testing phase, many tests were performed:

- Mean Absolute Error (MAE);

- Mean Absolute Percentage Error;

- Mean Squared Error;

- Root Mean Squared Error (RMSE);

- Correlation Coefficient (R).

After the best model was determined, the sensitivity analysis was done in order to evaluate the effect of each input on the output (Günaydin \& Doğan, 2004; Principe et al., 2010).

Strictly speaking, the data comprising information on 136 projects was grouped in following three sets:

- Training set contained 96 exemplars $(70 \%)$;

- Cross-validation set contained 20 exemplars (15\%);

- Test set contained 20 exemplars (15\%).

Therefore, the data were ready for analysing.

\section{RESULTS AND DISCUSSION}

The NeuroSolution 6 program for Excel analysed the ANN model. Training was applied for 1000 epochs, which ran 10 times for each of 1000 epochs. As it can be seen in Table 4, training was stopped in 38 process elements (PEs) at 3 runs when the minimum errors were achieved for both training and cross-validation datasets, where $\left(8.4 \cdot 10^{-8}\right)$ were for training data and $\left(9 \cdot 10^{-8}\right)$ for cross-validation data, in which they appear in the smallest values, and that indicates that the ANN is valid to estimate the cost and has been trained.

Table 4. Training and cross-validation process (developed by the author)

\begin{tabular}{|l|l|l|}
\hline Best Networks & Training & Cross Validation \\
\hline Hidden 1 PEs & 38 & 38 \\
\hline Run \# & 3 & 3 \\
\hline Epoch \# & 1000 & 1000 \\
\hline Minimum MSE & $8.42817 \cdot 10^{-8}$ & $9.00496 \cdot 10^{-8}$ \\
\hline Final MSE & $8.42817 \cdot 10^{-8}$ & $9.00496 \cdot 10^{-8}$ \\
\hline
\end{tabular}

In the network test process, the data from twenty projects were used to compare the actual costs with the estimated costs, which were obtained by the ANN model (Table 5). 
Table 5. Results of the testing process (developed by the author)

\begin{tabular}{|c|l|l|l|l|l|}
\hline $\begin{array}{c}\text { Project } \\
\text { No. }\end{array}$ & $\begin{array}{l}\text { Actual cost } \\
\text { (USD) }\end{array}$ & $\begin{array}{l}\text { Estimated } \\
\text { cost (USD) }\end{array}$ & $\begin{array}{l}\text { Absolute } \\
\text { Error AE } \\
\text { (USD) }\end{array}$ & $\begin{array}{l}\text { Absolute } \\
\text { percentage } \\
\text { error }(\boldsymbol{\%})\end{array}$ & Squared error \\
\hline 1 & 400000.00 & 400634.31 & 634.316 & 0.15 & 402357.10 \\
\hline 2 & 250000.00 & 249440.47 & 559.52 & 0.22 & 313071.26 \\
\hline 3 & 250000.00 & 248918.22 & 1081.77 & 0.43 & 1170233.20 \\
\hline 4 & 208744.12 & 208942.54 & 198.4217 & 0.09 & 39371.18 \\
\hline 5 & 155579.24 & 155882.51 & 303.27 & 0.19 & 91973.04 \\
\hline 6 & 261802.80 & 261795.50 & 7.30 & 0.002 & 53.29 \\
\hline 7 & 117077.44 & 117158.20 & 80.76 & 0.06 & 6522.57 \\
\hline 8 & 189822.00 & 189736.54 & 85.45 & 0.04 & 7302.00 \\
\hline 9 & 167441.86 & 167382.90 & 58.95 & 0.03 & 3475.50 \\
\hline 10 & 151325.85 & 151328.98 & 3.13 & 0.002 & 9.82 \\
\hline 11 & 198919.56 & 195229.21 & 3690.34 & 1.85 & 13618624.76 \\
\hline 12 & 204249.50 & 206367.85 & 2118.35 & 1.03 & 4487406.60 \\
\hline 13 & 183125.00 & 182953.08 & 171.91 & 0.09 & 29555.42 \\
\hline 14 & 429534.88 & 429660.27 & 125.39 & 0.02 & 15723.40 \\
\hline 15 & 175595.73 & 178272.12 & 2676.39 & 1.52 & 7163077.47 \\
\hline 16 & 5703400.00 & 5703451.68 & 51.68 & 0.0009 & 2671.13 \\
\hline 17 & 334883.72 & 334586.76 & 296.95 & 0.08 & 88180.27 \\
\hline 18 & 400000.00 & 400634.31 & 634.31 & 0.15 & 402357.10 \\
\hline 19 & 250000.00 & 249440.47 & 559.52 & 0.22 & 313071.26 \\
\hline 20 & 250000.00 & 248918.22 & 1081.77 & 0.43 & 1170233.20 \\
\hline Mean & $\mathbf{5 1 4 0 7 5 . 0 8}$ & & $\mathbf{7 2 0 . 9 7}$ & $\mathbf{0 . 1 4}$ & $\mathbf{1 4 6 6 2 6 3 . 4 8}$ \\
\hline & & & & & \\
\hline
\end{tabular}

As shown in Table 6, the Mean Absolute Error (MAE) was (720.79 USD), which means that it is acceptable amount compared to the total cost of projects. The Mean Absolute Percentage Error (MAPE) was (0.14 \%), which is less than 1 per cent indicating that the ANN model is able to predict the cost accurately and effectively with the smallest errors. Also, according to Shehatto (2013), the accuracy performance (AP) can be expressed as follows:

$\mathrm{AP}=100-\mathrm{MAPE}$

$\mathrm{AP}=100-0.14=99.86 \%$.

This value indicates that the network's accuracy is $99.86 \%$; thus, the ANN model is optimal for predicting the preliminary construction cost estimate in Yemen with the accuracy higher accuracy than that of traditional methods.

In this study, the RMSR was (1210.89 USD), which is low comparing to the total project cost (514075.08 USD), which indicates that the model is perfect to predict the cost. Therefore, RMSR points out that the performance of the ANN to predict construction costs in Yemen is characterized with high accuracy potential. Two values of absolute minimum and maximum errors were mentioned in Table 6 , these two values indicate that the Min. value (3.3 USD) is very small and the Max. (3 690.34 USD) is also a small value comparing to the total price of the project or the mean of the actual cost, which is (514 075.08 USD). Interestingly, these values 
provide reliable evidence about the efficiency of the ANN model, which can be widely used to estimate construction projects costs in Yemen. The correlation coefficient is considered another test of model performance. The $\mathrm{R}$ value was (0.999), which indicates there is a strong linear correlation between the actual cost and the estimated cost in the test phase. To increase efficiency of this study, the Mean Absolute Percentage Error (MAPE) was (0.14\%), the Shehatto's model MAPE was $6 \%$, the accuracy performance (AP) of this study's model was $99.86 \%$ and Shehatto's model accuracy performance (AP) was $94 \%$.

Furthermore, the correlation coefficient of this study was 0.999 whereas in Shehatto's model it was 0.995 . From the last comparisons, the model analysed in this study demonstrates larger values of test analysis than Shehatto's model, which indicates that the model analysed in this study is more efficient in estimating the preliminary costs. On the positive side, the correlation coefficient of regression model that was obtained by Arab (2011) was 0.608 of his predicted cost model; it was smaller than the correlation coefficient obtained in this study, which indicates that the artificial neural network's model investigated in this study is more efficient than the regression model considered in Arab's study.

Table 6. ANN performance results (developed by the author)

\begin{tabular}{|l|l|}
\hline Model's Performance & F. cost \\
\hline Mean Absolute Error (MAE) & 720.97 USD \\
\hline Mean Absolute Percentage Error (MAPE) & $0.14 \%$ \\
\hline Mean Squared Error (Willumsen et al.) & 1466263.48 USD \\
\hline Root Mean Squared Error (RMSE) & 1210.89 USD \\
\hline Min. Abs. Error & 3.13 USD \\
\hline Max. Abs. Error & 3690.34 USD \\
\hline$R$ & 0.999 \\
\hline
\end{tabular}

In order to understand the effect of each variable, the sensitivity analysis was required.

\subsection{Sensitivity Analysis}

It can be seen in Table 7 that the input variable (type of tiles $=154752.8$ ) had the largest value, which indicates that it has a significant influence on the estimated cost (output); the input variable (degree of complexity $=104568.84$ ) also has a significant influence on the output. It means any changes in those two parameters can affect the cost (output). In contrast, the variables (HVAC \& Project type) had the lowest values of impact on the cost, which indicates that they have a slight influence on the output (estimated cost), if they change. 
Table 7. Results of the sensitivity analysis about mean (developed by the author)

\begin{tabular}{|l|l|}
\hline Sensitivity & F. cost \\
\hline Type of tiles & 154752.86 \\
\hline Degree of complexity & 104568.84 \\
\hline Position & 46591.92 \\
\hline Floors height & 45964.03 \\
\hline Slab type & 43489.83 \\
\hline External finishing & 36103.83 \\
\hline Site area & 34666.41 \\
\hline Number of storeys & 24640.64 \\
\hline Floor area & 24285.11 \\
\hline Project type & 15797.79 \\
\hline HVAC & 7443.78 \\
\hline
\end{tabular}

Therefore, the effect of each variable on cost estimate was clear.

\section{CONCLUSION}

Considering the presented analysis and discussion, it may be concluded that the modern technique ANN proves to be highly effective and efficient for preliminary cost estimate with the smallest error.

This technique can be used by the Yemeni engineers and construction firms to estimate the costs of their projects faster and more accurately. In addition, this new technique can be widely adopted in the developing countries positively affecting the field of estimation.

The ANN technique might be implemented by many programs such as Excel, and NeuroSolution and is user-friendly. The ANN model depends on the collected data for a specific period and has many constraints, which should be considered. In this study, the data were collected from 2011 to 2015, which does not appear particularly useful at present; thus, the new data should be collected for the last five years. It can be further used for the detailed estimate in the tender stage. Thus, the preliminary estimate in Yemen should be developed using modern techniques such as the ANN technique.

\section{REFERENCES}

Arab, M. Z. M. (2011). A function-based cost model for early cost advice on new-build schools projects. Ph.D. thesis, Heriot-Watt University.

Arafa, M., \& Alqedra, M. (2011). Early Stage Cost Estimation of Buildings Construction Projects Using Artificial Neural Networks, Journal of Artificial Intelligence, 4(1), 63-75. https://doi.org/10.3923/jai.2011.63.75

Ashwood, A. J. (2013). Portfolio selection using artificial intelligence. Ph.D. Thesis, Queensland University of Technology, Australia.

Brook, M. (2011). Estimating and tendering for construction work (forth ed.). Amsterdam: Elsevier/Butterworth-Heinemann. 
Cheng, M.-Y., Tsai, H.-C., \& Hsieh, W.-S. (2009). Web-based conceptual cost estimates for construction projects using Evolutionary Fuzzy Neural Inference Model, Automation in Construction, 18(2), 164-172. https://doi.org/10.1016/j.autcon.2008.07.001

Dowler, J. D. (2008). Using neural networks with limited data to estimate manufacturing cost, M.Sc. Thesis, Ohio University, Industrial and Systems Engineering, USA. Retrieved from http://www.ohiolink.edu/etd/view.cgi?ohiou1211293606

Emsley, M. W., Lowe, D. J., Duff, A. R., Harding, A., \& Hickson, A. (2002). Data modelling and the application of a neural network approach to the prediction of total construction costs, Construction Management \& Economics, 20(6), 465-472. https://doi.org/10.1080/01446190210151050

Yu, A. T. W., Shen, Q., Kelly, J., \& Hunter, K. (2005). Application of value management in project briefing, Facilities, 23(7/8), 330-342. https://doi.org/10.1108/02632770510600281

Günaydin, H. M., \& Doğan, S. Z. (2004). A neural network approach for early cost estimation of structural systems of buildings, International Journal of Project Management, 22(7), 595-602. https://doi.org/10.1016/j.ijproman.2004.04.002

Hunter, K. (2014). Estimating preconstruction services costs for highway projects, M.Sc. thesis, Iowa State University.

Islam, M., Zhou, L., \& Li, F. (2009). Application of artificial intelligence (artificial neural network) to assess credit risk: a predictive model for credit card scoring. M.Sc. Thesis, Blekinge Institute of Technology.

Kim, G.-H., Shin, J.-M., Kim, S., \& Shin, Y. (2013). Comparison of School Building Construction Costs Estimation Methods Using Regression Analysis, Neural Network, and Support Vector Machine, JBCPR Journal of Building Construction and Planning Research, 01(01), 1-7. https://doi.org/10.4236/jbcpr.2013.11001

Kirkham, R. (2014). Ferry And Brandon's Cost Planning of Buildings, (9th ed.). Wiley: WileyBlackwell.

Kriesel, D. (2005). A Brief Introduction to Neural Networks. Available from http://www.dkriesel.com/en/science/neural_networks

Kshirsagar, P., \& Rathod, N. (2012). Artificial neural network, International Journal of Computer Applications, MPGI National Multi Conference, (MPGINMC-2012).

Pawar, R. (2007). Predicting bid prices in construction projects using non-parametric statistical models. M.Sc thesis, Texas A\&M University.

Principe, J., Lefebvre, C., Lynn, G., Fancourt, C., \& Wooten, D. (2010). NeuroSolution Help: NeuroDimension, Inc.

Samphaongoen, P. (2010). A Visual Approach to Construction Cost Estimating. M.Sc. thesis, Marquette University, e-Publications@Marquette. Available from https://pdfs.semanticscholar.org/5cfe/d1dae78921232323eceff19d23b9942c9f2f.pdf

Shehatto, O. M. (2013). Cost estimation for building construction projects in Gaza Strip using Artificial Neural Network (ANN). M.Sc. Thesis, The Islamic University, Gaza.

Sonmez, R. (2004). Conceptual cost estimation of building projects with regression analysis and neural networks, Canadian Journal of Civil Engineering, 31(4), 677-683. https://doi.org/10.1139/104-029

Willumsen, P., Oehmen, J., Stingl, V., \& Geraldi, J. (2019). Value creation through project risk management, International Journal of Project Management, 37(5), 731-749. https://doi.org/10.1016/j.ijproman.2019.01.007

\section{AUTHORS' SHORT BIOGRAPHIES}

Waled Hakami is an Assistant Professor at the College of Engineering, Architecture Department of the University of Science and Technology, Yemen. He received a Ph. D. degree in 2017 and M.Sc. in 2013 in Construction Management from Sudan University of Science and Technology, Sudan. He teaches Architecture and Construction Sciences for more than 6 years for undergraduate students. As well, he has worked as a site engineer and consultant at many projects in Yemen and 
Sudan for 10 years. His research interests concentrate on construction management, economics, and architecture.

E-mail:w_g2006@yahoo.com

Awad Hassan is a Professor at the College of Architecture and Planning in Sudan University of Science and Technology, Sudan. He received a Ph. D. degree in 2006 from the University of Khartoum, Sudan. He also received M. Sc. in 1986 in Building Economic and Management from the University College London, UK. He teaches architecture and construction sciences for more than 30 years for both postgraduate and undergraduate students. As well, he is the Dean of the College of Architecture and Planning in Sudan University of Science and Technology. His research interests concentrate on construction management and economics.

E-mail: awadshassan@yahoo.com

\section{APPENDIX 1}

Table 1. Data on one hundred-thirty-six implemented projects (developed by the author)

\begin{tabular}{|c|c|c|c|}
\hline Variable & Inputs & No. of projects & Percentage (\%) \\
\hline \multirow{7}{*}{ Project type } & Administration & 8 & 5.8 \\
\hline & Commercial & 16 & 11.7 \\
\hline & Educational & 24 & 17.7 \\
\hline & Residential & 48 & 35.3 \\
\hline & Mosques & 0 & 0 \\
\hline & Health centre & 40 & 29.5 \\
\hline & Total & 136 & 100 \\
\hline \multirow{3}{*}{$\begin{array}{l}\text { Degree of } \\
\text { complexity }\end{array}$} & Complex & 8 & 5.8 \\
\hline & Normal & 128 & 94.2 \\
\hline & Total & 136 & 100 \\
\hline \multirow{11}{*}{ Site area, $\mathrm{m}^{2}$} & $200-300$ & 32 & 23.5 \\
\hline & $301-400$ & 24 & 17.6 \\
\hline & $401-850$ & 24 & 17.6 \\
\hline & $851-1200$ & 8 & 5.9 \\
\hline & $1201-1350$ & 8 & 5.9 \\
\hline & $1351-1600$ & 8 & 5.9 \\
\hline & $1601-2050$ & 8 & 5.9 \\
\hline & $2051-2300$ & 8 & 5.9 \\
\hline & $2301-2750$ & 8 & 5.9 \\
\hline & $2751-11700$ & 8 & 5.9 \\
\hline & Total & 136 & 100 \\
\hline \multirow{4}{*}{ Project position } & Mountain & 40 & 29.5 \\
\hline & Coastal & 96 & 70.5 \\
\hline & Desert & 0 & 0 \\
\hline & Total & 136 & 100 \\
\hline \multirow{6}{*}{ Floor area, $\mathrm{m}^{2}$} & $100-200$ & 16 & 11.8 \\
\hline & $201-250$ & 24 & 17.6 \\
\hline & $251-300$ & 48 & 35.3 \\
\hline & $301-350$ & 8 & 5.9 \\
\hline & $351-400$ & 0 & 0 \\
\hline & $401-450$ & 24 & 17.6 \\
\hline
\end{tabular}




\begin{tabular}{|c|c|c|c|}
\hline & $451-500$ & 0 & 0 \\
\hline & $501-550$ & 8 & 5.9 \\
\hline & $>550$ & 8 & 5.9 \\
\hline & Total & 136 & 100 \\
\hline \multirow{5}{*}{ Number of storeys } & 1 & 32 & 23.6 \\
\hline & 2 & 72 & 52.9 \\
\hline & 3 & 8 & 5.9 \\
\hline & 4 & 24 & 17.6 \\
\hline & Total & 136 & 100 \\
\hline \multirow{6}{*}{ Floor height, m } & 3.1 & 16 & 11.8 \\
\hline & 3.2 & 24 & 17.6 \\
\hline & 3.3 & 8 & 5.9 \\
\hline & 3.4 & 40 & 29.4 \\
\hline & 3.5 & 48 & 35.3 \\
\hline & Total & 136 & 100 \\
\hline \multirow{5}{*}{ Type of foundation } & $\mathrm{Pad}$ & 136 & 100 \\
\hline & Strip & 0 & 0 \\
\hline & Raft & 0 & 0 \\
\hline & Piles & 0 & 0 \\
\hline & Total & 136 & 100 \\
\hline \multirow{4}{*}{ Slab type } & Drop beams & 96 & 70.5 \\
\hline & Hollow block & 24 & 17.7 \\
\hline & Flat & 16 & 11.8 \\
\hline & Total & 136 & 100 \\
\hline \multirow{3}{*}{ Interior decoration } & Luxury & 0 & 0 \\
\hline & Basic & 136 & 100 \\
\hline & Total & 136 & 100 \\
\hline \multirow{5}{*}{$\begin{array}{l}\text { Type of external } \\
\text { finishing }\end{array}$} & None & 0 & 0 \\
\hline & Normal plaster & 48 & 35.3 \\
\hline & Stones & 88 & 64.7 \\
\hline & Aluminium cladding & 0 & 0 \\
\hline & Total & 136 & 100 \\
\hline \multirow{5}{*}{ Type of HVAC } & None & 80 & 58.9 \\
\hline & Window & 32 & 23.5 \\
\hline & Split & 24 & 17.6 \\
\hline & Central & 0 & 0 \\
\hline & Total & 136 & 100 \\
\hline \multirow{5}{*}{ Type of tiles } & Ceramic & 128 & 94.1 \\
\hline & Terrazzo & 0 & 0 \\
\hline & Porcelain & 0 & 0 \\
\hline & Granite & 8 & 5.9 \\
\hline & Total & 136 & 100 \\
\hline \multirow{3}{*}{$\begin{array}{l}\text { Type of electricity } \\
\text { works }\end{array}$} & Luxury & 0 & 0 \\
\hline & Basic & 136 & 100 \\
\hline & Total & 136 & 100 \\
\hline \multirow{3}{*}{$\begin{array}{l}\text { Type of mechanical } \\
\text { works }\end{array}$} & Luxury & 0 & 0 \\
\hline & Basic & 136 & 100 \\
\hline & Total & 136 & 100 \\
\hline \multirow{3}{*}{ Basement } & Exists & 0 & 0 \\
\hline & Does not exist & 136 & 100 \\
\hline & Total & 136 & 100 \\
\hline
\end{tabular}

